Article

\title{
An Institutional Perspective on Business Planning Activities for Nascent Entrepreneurs in Sweden and the US
}

\section{Benson Honig ${ }^{1} *$ and Tomas Karlsson ${ }^{2}$}

1 Degroote School of Business, McMaster University, 1280 Main Street West, Hamilton, ON L8S4M4, Canada

2 Department of Managing Organisational Renewal and Entrepreneurship (MORE), Chalmers University, Vera Sandbergs Allé 8: 4 vån, Gothenburg 41296, Sweden

* Author to whom correspondence should be addressed; E-Mail: bhonig@ @mcmaster.ca; Tel.: +905-525-9140 (ext. 23943).

Received: 27 September 2013; in revised form: 16 November 2013 / Accepted: 18 November 2013 / Published: 21 November 2013

\begin{abstract}
We compared nascent characteristics and behaviors leading to business planning activities in Sweden with the United States (US), examining the effects of institutional pressures exerted in the different countries. We analyzed institutional factors leading 362 Swedish and 347 US entrepreneurs to write plans during a two-year period. We show that national cultures moderate how institutional pressures influence nascent behaviors, questioning generic applications of institutional theory. We found business planning behaviors moderated by nationality, showing significant and negative effects for business classes in the US. Implications are drawn for institutional theory and the study of nascent businesses, as well as for normative business planning literature and practice of nascent businesses.
\end{abstract}

Keywords: institutional theory; cross national entrepreneurship; business planning

\section{Introduction}

Best practices frequently suggest that entrepreneurs write business plans before beginning the task of setting up an organization, delivering a product or service, and entering the marketplace. However, not all entrepreneurs write plans, and many successful entrepreneurs avoid taking this "best practice" route altogether [1-3]. Further, bounded rationality constrains the ability to successfully evaluate and 
predict future events [4-6]. It severely reduces the applied practical utility of business planning, in that anticipating future events is difficult, if at all possible, compounded by cognitive limitations on the range and number of alternatives that may be examined in any one plan. In this study, we seek to understand the forces exerted on entrepreneurs to conform to business planning behavior, which persists in spite of a lack of conclusive evidence connecting planning with efficiency. We examine the institutional characteristics that influence the behavior of independent nascent organizations with respect to business plans, and how such characteristics may be moderated by cultural factors. The concept of nascent organizations to indicate genuinely new activities that take place before individuals have actually started their firms (they have neither registered a firm, nor have they been able to pay salaries for 3 consecutive months), but have engaged in an activity indicating an attempt to start a firm, i.e., a gestation activity [7]. Our focus is on written formal business plans, in two populations (Sweden and the US) of nascent entrepreneurs observed over a 24-month period.

This study joins a small but growing number of entrepreneurship articles that utilize an institutional perspective to explain entrepreneurial behavior [2,8-12]. Nascent organizations face a different set of problems than their established counterparts. They must raise capital from sources skeptical of newcomers, recruit employees that are unaware of what the firm is doing, obtain new resources, and initiate their product and market, among other things. Related to these problems, nascent organizations have a relative lack of legitimacy [13,14]. In order for them to successfully come into existence, they have to get know their stakeholders, earn their respect and follow the norms and rules they pose. Organizations typically strive for legitimacy for the purpose of mobilizing the support of external stakeholders who have crucial influence over "how the organization is built, how it is run, and simultaneously, how it is understood and evaluated" [15]. Consequently, legitimacy is the means through which rules and resources shape organizational actions [16]. Studies on the legitimacy of new ventures emphasize the importance of external legitimacy for the enhancement and survival of the firm, mainly through aligning the firm's activities and forms with its environment $[17,18]$. Business plans can thus be viewed as providing external legitimation to venture capitalists, investors, employees, and customers.

Legitimation indicates that new ventures benefit by conforming to institutional pressures, and business planning should positively affect the performance of new ventures [19,20]. However, proof regarding this assertion is scarce. There is some indication that specific planning characteristics and behaviors may result in positive performance for certain types of ventures. In addition, there is some evidence that planning leads to persistence [3,10,20,21]. However, persistence by itself is a poor measure of success. Entrepreneurs may be better off identifying failure early on, rather than pursing an activity that will likely lead to failure. One study examining the relationship between planning and failure found only weak relationships between non-planners and failure [3]. Entrepreneurship research thus ends up inconclusive as to the effect of business planning on the success of nascent organizations [22].

Sarasvathy [5,6] points out that rational choice models, for which business planning is derived, are based on assumptions that may not hold in the actual entrepreneurial environment. She asks "how can an entrepreneur act rationally in cases where the information is isotropic" [6]. In short, it is unclear ex ante what will be the most important aspects of the environment, for planning purposes, and which are irrelevant. Since the evidence supporting causal planning assumptions is frequently violated, as when entrepreneurs succeed without planning [1-3] we are left to examine other theoretical 
frameworks, beyond those that are based on causal assumptions, to explain the prevalence of business planning activities. Institutional theory is one of the most prevalent theories for explaining isomorphic activities in organizational fields [23-25]. For example, Honig and Karlsson [26] investigated the link between institutional antecedents and business planning, finding that institutional variables, such as coercion and mimetic forces, are important predictors influencing the propensity of new organizations to write business plans. In this study, we utilize the framework they developed, examining the diffusion of business planning according to mimetic, coercive, and normative forces in the US context, for cross-national comparison. We add to their work by examining the impact of culture on the diffusion and strategic response to institutional pressures [27].

\section{Institutional Forces and the Behavior of New Organizations}

Early versions of institutional theory have realist underpinnings, taking an interest in how institutional systems impose constraints on organizations through rule and norm systems [28]. In what is often referred to as a neo-institutional turn in institutional theory, there was a turn to how social realities were shaped [29]. The neo-institutional turn takes a keen interest in the homogeneity of practices and arrangements found across organizations [30]. It occupies one of the most central and prevalent perspectives of organizational analysis [23]. Of interest to institutional scholars is the distinction between the importance of structure, and that of agency. Scholars seek to understand whether isomorphism is the result of existing structural forces, or whether it reflects actors' attempts to manipulate or deviate from the environment toward their own advantage [23]. Understanding how institutional behavior emerges and diffuses is thus central in understanding the strategic responses that will occur [26], allowing for a better understanding of the structure versus agency debate. Institutional pressures have predominantly been studied in older and larger organizations. In this paper, we extend neo-institutional theory into the setting of emerging organizations, where forces and responses are still emerging. The term "institution", itself, is frequently used to characterize large, inflexible, old organizations. However, entrepreneurship scholars have shown relationships between founding rates and institutional factors at national levels [31]. Little is known about how institutional pressures play out on a micro level in nascent organizations, and even less about their ability to respond to institutional pressures in a specific way.

Organizational variables, such as resources and identity, pose a potential influence on the organization's possibility or desire to conform to an institutional pressure. Organizations in munificent environments, enhanced by abundance of unique resources, should be more resistant to power-dependent relations of institutional agents, and less subject to such pressures. This implies that small organizations are less resistant to institutional pressures than their larger counterparts. Thus, nascent organizations are less resistant to institutional pressures than older ones, in part due to their smaller size. Some previous scholarship suggests that nascent organizations are strongly subjected to institutional pressures, as they must establish new connections to the business world [15,27].

Thus, a nascent organization must show credibility in order to establish necessary exchanges. Arguably, establishing a new exchange is more complex than maintaining an existing one. Hence, some claim that nascent organizations maintain a liability of newness, leaving them susceptible to institutional pressures $[13,14]$. By studying the responses of nascent organizations to institutional 
pressures, we examine how institutional forces play out in organizations with weak power positions and significant resource scarcities.

DiMaggio and Powell [29] argue that three forces drive the processes in which firms and organizations become similar, what they call isomorphic pressures. These pressures are coercive, regulative and mimetic. In combining these forces, institutional theory focuses on how social relationships and actions become taken for granted, and how our cognitive set of shared meanings and possible actions are constructed [28]. DiMaggio and Powell's article is often read selectively, where mimetic isomorphism has received the most attention [23]. Following the suggestion of Mizruchi and Fein [25] we try to understand the process in which organizations become similar from several different perspectives.

In Figure 1 below we illustrate the key relationships in the study.

Figure 1. Institutional forces, sources and the moderating effects of culture on business planning.

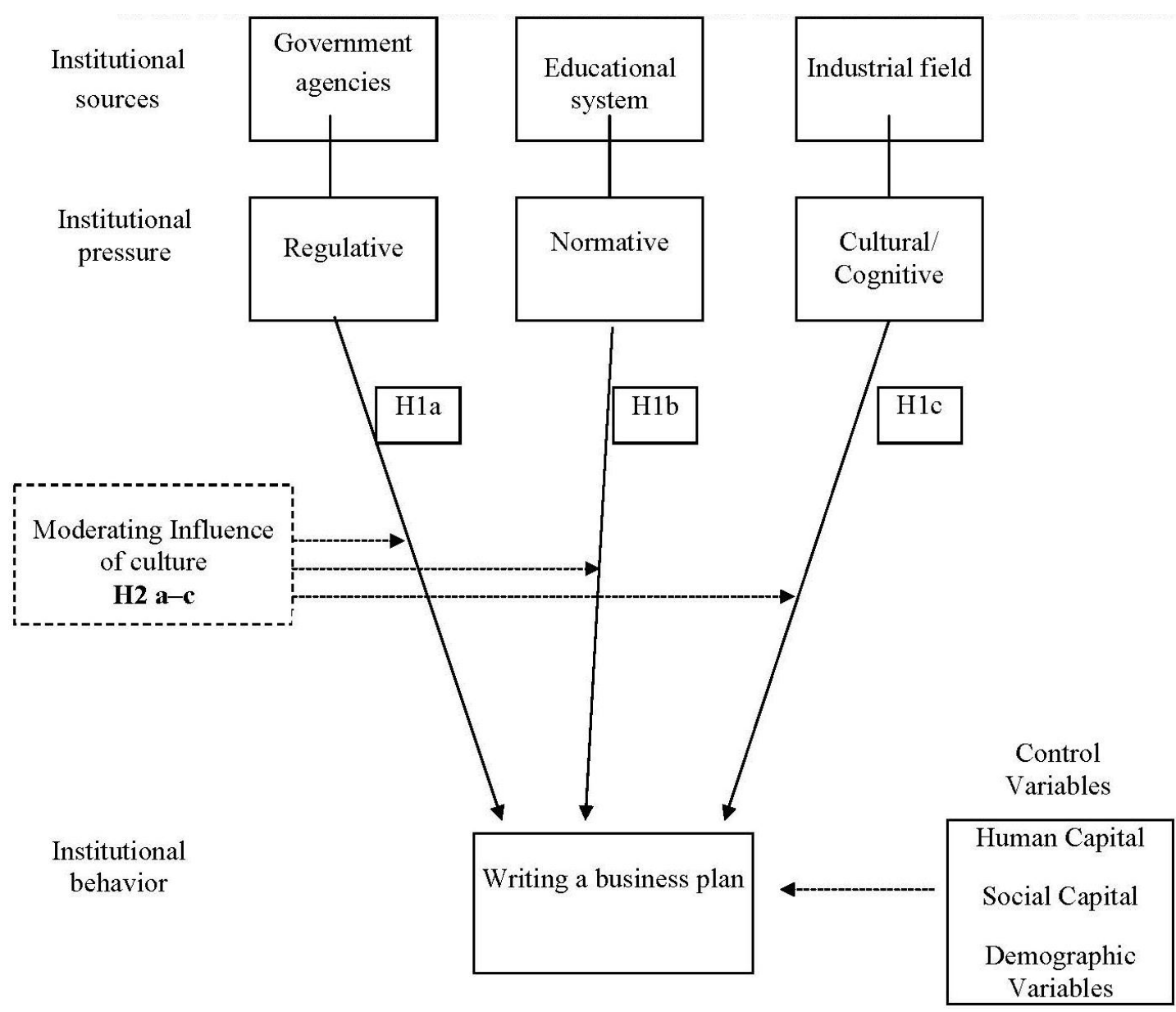

We view pressures as originating from specific institutional sources as depicted in the figure. Coercive pressure is upheld by government agencies, normative by the educational system and mimetic pressures by other organizations within the institutional field [32]. We theoretically and empirically distinguish mimetic isomorphism from coercive and normative forces. Thus, we attempt to empirically isolate the individual effects of these forces. Very few studies explicitly control for coercive and normative influences, a critical factor when attempting to isolate mimetic isomorphism [23,25]. 


\section{Coercive Isomorphism}

The regulative element works through coercive isomorphism. Coercive isomorphism is a term explaining the phenomena of conformity of actors subjected to the regulative element. It results from both formal and informal pressures exerted on organizations by other organizations upon which they are dependent. Such pressures may be felt as force, or persuasion [33].

Sources for the regulative element are connected primarily with authority. It is commonly connected to governmental activities, be it law and enforcement or benefit programs of different kinds. Governmental institutions have a unique position because they can influence organizations and individuals with legitimate coercion. Empirical studies have examined governmental influences on organization activities, e.g., how property laws have influenced the organizational activity [34], and how governmental constraints affected organizations in early US telecommunication [35].

Looking at the regular element as a stable formal/informal regulatory system with enforcements, we may find other types of sources for the regulative element than governmental organizations. Organizations such as banks, large and old corporations, and non-governmental institutions are also likely sources for the regulative element. These actors often have stable formal authority with a lot of power that fulfills a similar function to laws, and legitimates coercion. A powerful actor is one that is capable of enforcing its rule system such that the organization must comply.

In the case of business planning, to our knowledge, there is no legislative framework that requires organizations to write business plans, but there are other formalized pressures that influence nascent organizations into doing so. Nascent firms frequently have relationships with assistance agencies at both national and regional levels. Examples include the SBA (Small Business Association) in the US, and employment offices, regional development facilities and incubators, world-wide. These organizations often place constraints on nascent entrepreneurs, mandating that specific resources or various forms of assistance are contingent on their participation in other unrelated activities [36]. In Sweden, a business support agency provides potential entrepreneurs with technical and financial support on condition that they complete an approved business plan. We formulate our first hypothesis as follows:

Hypothesis 1a: Nascent organizations whose founders have relationships with public support agencies have a greater propensity to produce business plans than those without those relationships.

\section{Normative Isomorphism}

Professions are strong institutional constituencies influencing organizations. They exercise a different type of control from governments. Professions control through ideas, and belief systems. "They exercise control by defining reality - by devising ontological frameworks, proposing distinctions, creating typifications, and fabricating principles or guidelines for action" [37]. Scholars utilizing an institutional perspective often use professions as their unit of analysis.

DiMaggio [38] studied US art museums and the professional norms related to them to understand the norms exerted by professions on independent organizations. He found that professionalization both enforced existing institutions and was a source for de-institutionalization. Likewise, Meyer and 
Rowan [24], found similar relationships in educational organizations. Brint and Karabel [39] argue in their conclusions that professionals within an organization are the carriers of that organization's interest. Educational systems and family are important sources of institutionalization, as they shape social norms about personal behavior and attitudes to work methods, relevant problems. In addition, they influence actors' worldviews, and roles [32]. Thus, professional organizations, norms, and associations are likely to influence the internal activities of organizations, irrespective of arguments based on efficiency.

The worldwide growth of the business school at both the undergraduate and MBA level, along with the increasing professionalization and diffusion of management education, are normative processes in their own right. The interests of such stakeholders converge on a number of relevant points. Courses that typically instruct students in the art of writing a business plan are supported by academic scholarship, appointments, journals, conferences, and doctoral programs. Consequently, the publication of business plan literature for universities escalated beginning in the 1980's. Another large source for normative texts on business plans are educational books in entrepreneurship, typically targeting entrepreneurship students in colleges and universities [40-44]. Many universities, e.g., Babson College, Harvard Business School, and numerous American and European Business Schools give courses in entrepreneurship. A major part of the curriculum in these courses includes business planning exercises, and practical work with the production and even presentation of a business plan.

Business plans are a major part of much of the curricula at many Universities and therefore, we expect that business plans are taught as something good, an activity that each and every new organization should complete. As a test of a normative isomorphic pressure, we include the importance of business education in our second hypothesis:

Hypothesis 1b: Nascent organizations whose founders have been subjected to normative isomorphism (e.g., a business education) have a greater propensity to produce business plans than those whose founders have not been subjected.

\section{Mimetic Pressures}

Mimetic isomorphism is a result of organizations attempting to limit uncertainty by modeling their behavior after similar successful organizations in their field [29,45,46]. An entrepreneur familiar with the business plan written by a known successful entrepreneur may endeavor to write one him or herself. From a procedural point of view, TQM, SWOT analyses, and business plans all represent diffusion based on mimetic opportunities that appear in particular sectors. For example, Brown [47] found that all 29 cases of the manufacturing firms he studied used business plans, and reviewed them either annually or at 18 month intervals.

Mimetic behavior may also be the result of attempts to gain legitimacy in the eyes of other members of the organization. Actors may provide what seems to be a rational approach to planning, one that appears to have succeeded elsewhere. Institutionalization is frequently determined by industry location, where mimetic processes are easily observed. Mature industries provide the opportunity for mimetic isomorphism because new entrants have an opportunity to observe and learn from the established competitors [22]. The emergence and diffusion of the Hollywood studio system is one such example [48]. Jones [49] demonstrated the liability of new industries by showing how legitimating 
forces redefined the development of the film industry, as it migrated from regulatory to cultural legitimacy. In the emerging film industry, institutional rules changed for both technological entrepreneurs and content (cultural) entrepreneurs, so altering the mimetic approaches taken by competitors as the environment matured. Only once the "rules of the game" were well entrenched, were a common set of strategic mimetic approaches possible and/or desirable.

Nascent organizations imitate existing organizations within their industry, particularly in aspects deeply embedded into the industrial sector's cultural norms. This method of measuring mimetic isomorphism has been used by several researchers. Mezias, for example, examined the accounting practices of the largest 200 non-financial corporations in the US for generally accepted accounting principles, and Burdos examined the adoption of early retirement programs in Canadian Universities [50,51].

Manufacturing firms are subjected to similar physical and structural constraints, as well as engaging in more precise, unforgiving, mature and developed processes. They require highly specialized plants with similar human capital, technical, and infrastructural resources. Many practices conducted in manufacturing such as the use of lean manufacturing, as conducted by Toyota, and Total Quality Management [52], are the result of mimetic processes that firms incorporate irrespective of economic or efficiency [53]. Institutional forces thus affect the system of manufacturing practices, which may or may not lead to performance outcomes. Manufacturing typically requires a more complex supply chain, with revenues allotted at the proper time, reflecting the needs for research and development prototyping, production, marketing, sales, human resource, and inventory control. Planning, for systems that are well established and do not have too much variance (e.g., producing a refinery) is likely to provide advantages of efficiency, that will be copied by other entrants. For example, in a study examining 39 automotive assembly plants worldwide, high involvement work practices similar to those practiced by Japanese manufacturers diffused irrespective of efficiency gains, such as reduced defects. Further, the rate of adoption of the practices was found to be independent of complementary practices and technologies or factory productivity [54]. Benchmarking occurs, through the use of best practices, diffused by partnerships, inter-organizational networks, consultancy firms, and trade conventions [52]. We agree with Ketokivi and Schroeder's assertion that operations management, which focuses on routines, can be well informed by the institutional perspective that provides a theory of organizational mimicry. We thus maintain that manufacturing firms are more likely to undertake similar mimetic planning activities than other sectors, such as sales, marketing, and services, whose fundamental processes are more amenable toward new modes of operation, and are more flexible in their structure.

Hypothesis 1c: Nascent manufacturing organizations have a greater propensity to produce business plans than those in other industrial fields.

\section{Culture and Institutions}

Norms of management processes may not be universal. Indeed, research on national cultural values suggests equal strength across national cultures. Adoption of institutional pressures in general is likely effected by national cultural values. Institutional theory depends on the influence of groups upon the individual, be it state, religion or industrial peers. In general, we expect institutional pressures to 
influence Swedish nascent companies more strongly than US companies. While aspects of culture are used to explain the predicted relationships, culture is not analyzed directly. Instead we analyze the differential effect of cultural and other differences on a national level between Sweden and the US. In the paragraphs below we develop the hypothesis towards the specific national cultures.

The type of culture in their environment likely has a pivotal role in how new ventures react to institutional pressures. US corporate culture and Swedish corporate culture are growing increasingly similar, as both cultures are essentially meritocratic and market oriented. However, they still differ in some significant ways. Swedish culture could be described as egalitarian and cooperative [55]. Even cooperation between companies within the same industry exists without people taking much notice. This presents a very different culture from the US, which is usually thought of as an anti-regulative, non- corporatist, individualist culture [56]. The role of the state in the two countries is also largely different. The Swedish state traditionally has had active policies supporting Swedish industry, suggesting their entrepreneurs hold a more positive view toward adapting to changing rules and regulations implemented by the state. Hofstede, for example, when measuring individualism versus collectivism, found the US to be an outlier with 91, and Sweden a more moderate 71 , where the mean of individualism - collectivism was calculated at 50 [23].

Many people in the US see freedom of individual decision making as the reason for their nation's greatness [56]. They may therefore be less positive towards relying on outside sources for consultation and decision making. Swedes are also believers in individual decision making. However, many Swedes believe that individual decision making is insufficient for distributing wealth. They would therefore be more willing to let governmental directives guide the behavior of individuals and corporations [55]. Such general tendencies may influence the general propensity to comply with institutional pressures. Specifically, we suggest that new ventures situated within individualist cultures will be less likely to subsume to institutional pressures, while new ventures situated in collectivist cultures will be more likely to subsume to institutional pressures. In Figure 1 we illustrate the relationship between institutional sources and their institutional forces, as moderated by culture on planning behavior. These primary pressures originate from specific institutional sources as depicted in the figure.

We argue that regulatory forces should be stronger predictors of business planning in Sweden than in US. As an example, the employment office in Sweden can enforce their evaluation of business plans by distribution of governmental grants [57]. In contrast, the SBA, being a federal authority, adheres to bureaucratic evaluation criteria independent of a formal written business plan. This leads to our next hypothesis:

Hypothesis 2a: Relationships with assistance agencies will have a positive correlation to writing a business plan. This effect will be stronger for Sweden, than the US (it will be positively moderated if the company is located within Swedish culture).

Positive normative statements regarding business planning in new organizations emerged in US in the late 1950s, and spread widely through business schools and books on how to write business plans. The phenomenon, as such, is more novel in Sweden, yet it has already reached the curricula of most Swedish business schools. 
In 1977, only $4 \%$ of Swedish students elected to study in Business subjects, versus $15 \%$ for the US in 1975-1976 [58,59]. By 1992, the percentage in Sweden had grown to $11.8 \%$ while that in the US it had grown to $22 \%$. While it is less common for Swedish students to elect a business class subject, the relative impact of taking a business class subject is likely to be greater in Sweden than in the US. Business education in Sweden is highly uniform, and entrepreneurship courses are commonly part of the core curriculum in Sweden [60], while it is still most commonly an elective course in the US [61].

Because business education is more uniform in Sweden than in the US, we expect business education to have a stronger effect in Sweden in comparison with the US. An additional explanation is that business planning books for new ventures are much more common in the US than in Sweden. This type of book for new ventures first arose in the US [62]. A search through the Library of Congress data base in the US renders more than 100 books on how to write business plans, published in English. In contrast to the US, there are only a few books written on business planning in Swedish (e.g., [63,64]). Therefore, it is not necessary to attend business school or take a business class to be aware of the business plan in the US. However, in Sweden, business schools will be one of the few sources for normative pressures to write business plans. We thus hypothesize as follows:

Hypothesis 2b: Effects concerning business education and the propensity to write business plans are negatively moderated by US culture.

We also anticipate higher levels of mimetic pressure within the manufacturing industry in Sweden than in the US for two reasons. First, Swedish culture is generally considered more positive to inter firm collaboration. Firms are expected to be collaborative to other firms within the same industry and to companies outside their industry. One reason for the intra-industry inter-firm collaboration within the manufacturing industry is the long standing tradition of employers collaborating as a counterforce to national labor unions. This has resulted in a culture of collaboration in among the top management teams across organizations, particularly within manufacturing sectors. Contrary to this, we expect firms in the US to have very little tradition of intra industry collaboration. Companies within the same industry are generally viewed as competitors, and collaboration, if feasible, is associated with low levels of trust [65].

Companies outside the industry would usually be perceived as less of a threat. Therefore, specific industry affiliations would play less of a role in the US than they would in Sweden. Higher trust levels of Swedish people could also influence the amount of mimetic isomorphism. Research has shown that Swedish teenagers have higher trust towards people in general, than US teenagers [66]. Our final hypothesis is formulated thusly.

Hypothesis 2c: Effects concerning industry affiliation are negatively moderated by US culture.

\section{Methods}

In this research, we examine the role of business planning for 709 nascent entrepreneurs, 362 from Sweden and 347 from the US. The data were obtained from two different, but conceptually matched, research activities that occurred in the 48 contiguous states and in Sweden. The research methodology consisted of randomly selecting people and asking them if they, alone or with others, were in the process of starting a new business. Nascent entrepreneurs were individuals actively engaged in trying 
to start a new firm of their own, that was not covering operating expenses and salaries for more then three months. If they were covering expenses and salaries for more then three months, they were considered new businesses and therefore excluded from the analysis.

\subsection{Sample}

The study of emerging organizations is important, but little is still known about the process in which they start [67-69]. A major reason is that nascent organizations are inherently difficult to study. Most of them do not show up in firm databases, as they have not yet registered their firms. Neither are they captured in databases because of tax payments or the like. Consequently, data about them are not are not readily obtainable from traditional sources. This research was therefore uniquely designed to provide population estimates for business start-up efforts, and to follow a random sample of nascent activities leading to the possible start of new businesses by studying so called gestation activities.

In the US, 15,118 people were approached between July 1998 and April 1999, with 446 completing an initial detailed phone sample [70]. A follow up study; was conducted at 12 and 24 months, but was not used in this research. As nascent entrepreneurs we counted only those who were fully independent start ups, and who did not yet evidence start up activity (or were registered as a business). In total this resulted in 817 cases in the PSED database. We only included those companies with a complete set of data. Missing and erroneous data reduced the sample size to 438, with further reductions (explained shortly) to 347. The Swedish data are based on two samples of randomly selected individuals living in Sweden, individuals aged between 16-70 years and individuals aged between 25-44 years. The purpose of the first sample was to get a representative sample of the adult population in Sweden, and the second to increase the yield of nascent entrepreneurs, as indicated by previous research [7]. An enriched 25-44 year old cohort biases our population. This over sampling was done to increase the yield of nascents. The initial interviews were conducted during the period of May-September 1998. The qualified nascent entrepreneurs were contacted for follow-up interviews after 6, 12, and 18 and 24 months, but these were not used in our analysis. In Sweden, 35,971 individuals were contacted for telephone interviews, 30,427 individuals (84.6\%) agreed to participate, yielding a sample of 362 nascents for our comparative analyses. Several steps were undertaken in order to ensure that the Swedish and the US data was completely comparable. In the US data set cases where the respondent started up a business for an employer were eliminated (in exactly the same way as it was done in the Swedish cases). In total, seven cases were removed due to this reason. Similarly, cases coded as "purchase or take over of an existing business", or "start up sponsored by existing business", were removed. In total, 37 cases were eliminated due to this reason. Lastly, cases coded as "spouse only owns the company" were removed, as this indicated no respondent continuity between the first interviewee and subsequent interviews. In total, four cases were eliminated for this reason. Although the original data sets were designed to be representative for the entire population, the elimination of a few cases to assure a full data set means that the representativeness is limited.

\subsection{Dependent Variable}

We examined factors leading individuals to produce a written formal business plan for external use. Confirmation of writing a business plan was in response to the following question: "Have you 
prepared a business plan"? Only those who indicated they had completed a formal written plan were identified with a dummy variable. Many types of planning efforts can be called business plans. They may, for example, be scribbled down or exist only in the head of the entrepreneur. However, in this paper we view only formal written business plans as conformity to the business plan institution. We also acknowledge that formal written business plans, in themselves, have a variety of differences in quality and purpose. We use formally written business plans as our dependent variable as it constitutes a tangible artifact indicating conformity to the business plan institution.

\subsection{Independent Variables}

As independent variables we used variables deducted from institutional theory, c.f. DiMaggio \& Powell [29] and Scott [32]. Contact with a business support agency indicated coercive pressure. A dummy variable was created identifying those nascent entrepreneurs who indicated they had contact with a business support agency at any time before the initial interview. If a new venture wants support from a support agency, they are commonly required to write a business plan, some entrepreneurs may, of course, contact the agency and refuse to write a business plan and therefore forfeit the chance to get a support grant.

Our indicator of normative pressure measured if a nascent entrepreneur had completed a business class. Business education is well known to follow particular trends and fads [71], and we predicted that nascents who experienced business education would demonstrate their exposure to normative planning forces. A dummy variable indicated those who completed a business class at any time before the initial interview.

We used industry measures to identify mimetic isomorphism by identifying the completion rates of nascent by industrial sector. We initially coded dummy variables for industry by service, trading, manufacturing, and undeclared, examining the outcomes. Manufacturing firms represented the highest percentage of firms that completed business plans. As the previous research and theory discussed earlier supported this finding, we used nascent entrepreneurs in the manufacturing sector to indicate mimetic isomorphism [10,52]. We also tested the relationship between major equipment purchase and planning in the final model. As an additional test, we analyzed if businesses requiring heavy investments in the start-up phase would write business plans to a higher degree, due to increased exposure to demands of financial institutions and therefore partially echoing the argument of coercive pressures. Surprisingly, the major equipment purchase variable was negative and not significant. The variable was therefore dropped from later analysis.

\subsection{Moderating Effect}

In this study, we used country belonging as a proxy for national culture. Obviously, a crude measure such as the national belonging of a business start up does not capture all aspects of culture. However, nationality is an important aspect of culture and the comparisons of nationalities can be used to understand cultural differences. US entrepreneurs were coded 1, and Swedish entrepreneurs were coded 0 . This was then used in the subsequent analysis to investigate moderating effects. 


\subsection{Control Variable}

We use the same control variables in all equations. Human capital in general, such as years of education, managerial work experience, and adult education, is an investment that may produce labor productivity increases [72,73]. We controlled for human capital in several ways. Owners indicated the highest level of education they had completed, and this was coded into number of years. We tested both education in years, and years squared. None of the variables were significant in any of the regressions. We therefore kept the education in its normal form in the regressions. Respondents were also asked their total years of supervisory or managerial experience. We tested the amount of years of supervisory or managerial experience in both squared and normal forms. None of them showed any significance in any of the regressions. The amount of years of experience was therefore kept in its normal form in the regressions. Individuals who had previously attempted a start-up were also noted, and coded as having previous start up experience, indicated by a dummy variable.

Social capital refers to the ability of actors to extract benefits from their social structures, networks, and memberships [74-76]. Most of our social capital control variables were designed to examine individual networks. Parental networks were coded from if either parent had ever owned a business before. A variable was also constructed for those individuals who indicated that their family, relatives, and close friends were encouraging of their starting a business. An additional personal network variable controlled for if and when the nascent entrepreneurs indicated they were a member of a start-up team. We also asked respondents if they had received very strong or strong encouragement from family or friends to start a business.

In many countries, gender has been found to be a significant factor in the probability of establishing a business $[77,78]$. We thus included gender as a control.

The progression of the exploitation process, in terms of the number of gestation activities being undertaken, has previously been shown to be related to nascent entrepreneurial activity [79-81]. We utilized a count for 13 gestation activities, as controls, for the progress nascent entrepreneurs had made in their evolution. We used the full set of gestation behaviors, subtracting the ones used in the main regression.

Table 1 below lists the gestation behaviors used in this study.

Table 1. Gestations Behaviors counted in control variable.

\begin{tabular}{ll}
\hline 1 & Start up team \\
2 & Marketing/Promotion \\
3 & Patent \\
4 & Raw materials \\
5 & Equipment (Major item) \\
6 & Projected financial statement \\
7 & Invested money \\
8 & Approach Financial Institution \\
9 & Credit with supplier \\
10 & Arranged child care \\
11 & Full time devotion \\
12 & Employee hire \\
13 & Income goods/services \\
\hline
\end{tabular}


An additional control was if the company had asked others or financial institutions for funds. Certain banks and financial firms are known to insist upon viewing a written business plan before providing financial resources. Those entrepreneurs who asked financial institutions for financial assistance were identified in the equations with a dummy variable.

We used hierarchical multiple logistic regressions to determine the influence of predictor and control variables on the dichotomous outcomes specified by our hypotheses. This provided three equations, the first examining the controls, and the second testing the model without interaction effects (Hypothesis $1 \mathrm{a}-\mathrm{c}$ ) and the third testing the full model with interaction effects $(2 \mathrm{a}-\mathrm{c})$. We followed the method developed by Hosmer and Lemeshow [82] using maximum likelihood estimators to give logistic probabilities, where the computed matrix of covariates and dependent variables are assigned logistic probabilities.

\section{Findings}

Table 2 provides descriptive statistics for the variables associated with our hypotheses.

Table 2. Nascent entrepreneurs: descriptive statistics (US-weighted).

\begin{tabular}{ccccc}
\hline Variable & $\begin{array}{c}\text { US and } \\
\text { Sweden n(\%) }\end{array}$ & $\begin{array}{c}\text { US } \\
\text { (Dummy Mean) }\end{array}$ & $\begin{array}{c}\text { Sweden } \\
\text { (Dummy Mean) }\end{array}$ & $\begin{array}{c}\text { T (Sig) } \\
\text { (weighted) }\end{array}$ \\
\hline Wrote a formal plan & $145(0.20)$ & $62(0.18)$ & $83(0.23)$ & -1.67 \\
Years Education & 13.9 & 15.01 & 12.92 & $11.41 * * *$ \\
Years experience as manager & 6.9 & 8.67 & 5.2 & $5.82 * * *$ \\
Previous start-up experience & $165(0.23)$ & $85(0.24)$ & $80(0.22)$ & 0.75 \\
Parents in business & $351(0.50)$ & $177(0.51)$ & $174(0.48)$ & 0.78 \\
Encouraged by friends or family & $485(0.68)$ & $211(0.61)$ & $274(0.76)$ & $-4.30 * * *$ \\
Gender & $244(0.34)$ & $140(0.40)$ & $104(0.29)$ & $3.27 * *$ \\
Asked Finance for Funding & $150(0.21)$ & $68(0.20)$ & $82(0.23)$ & -0.99 \\
Gestation Behaviors & 4.7 & 5.38 & 4.02 & $6.99 * * *$ \\
Contact with assistance agency & $202(0.28)$ & $54(0.16)$ & $148(0.41)$ & $-7.82 * * *$ \\
Ever took a business class & $268(0.38)$ & $144(0.41)$ & $124(0.34)$ & $1.99 *$ \\
Manufacturing & $46(0.06)$ & $4(0.01)$ & $42(0.12)$ & $-5.87 * * *$ \\
\hline $\mathrm{N}$ & 709 & 347 & 362 & 709 \\
\hline
\end{tabular}

While $25 \%$ of all nascents wrote a business plan, the percentage was higher in Sweden, with $30 \%$ versus $21 \%$ in the US. These differences were statistically significant, and Swedes were significantly more likely to write a business plan (SD 0.048). The population had more education in the US, with 15.0 years versus 12.9 for Sweden, a statistically significant difference. US nascents also had more managerial experience (8.7 versus 5.2 years), although their marginally higher previous start-up experience failed to be statistically significant (24\% in US versus $22 \%$ in Sweden). The populations were slightly different regarding having parents in business (51\% and $48 \%$ in Sweden). The Swedish population was much more likely to be encouraged by family and friends (76\% versus $61 \%$ for the US). Women were more likely to be nascents in the US (40\%) than in Sweden (29\%). While entrepreneurs in the two countries were equally prone to ask financial institutions for funding, US nascents were 
more likely to report a higher number of gestation behaviors than the Swedes (5.38-4.02). A very large gap existed on the measures of agency assistance. While only $16 \%$ of the US population of nascents indicated they had contact with assistance agencies, $41 \%$ of the Swedish population had such contact. Finally, the US population was somewhat more likely to have taken a business class ( $41 \%$ versus $34 \%$ ), and far less likely to be in manufacturing (1\% versus $12 \%$ ). Table 3 below shows a hierarchical logistic regression, examining who wrote a formal plan as the dependent variable.

Table 3. Nascent Entrepreneurs: Most likely to plan US and Sweden together (HLS).

\begin{tabular}{|c|c|c|c|}
\hline Independent Variables & $\begin{array}{c}\text { Equation } 1 \\
\text { Controls }\end{array}$ & $\begin{array}{c}\text { Equation 2 } \\
\text { With independents }\end{array}$ & $\begin{array}{c}\text { Equation 3 } \\
\text { With interactions }\end{array}$ \\
\hline \multirow{2}{*}{ Years education } & 1.001 & 1.046 & 1.052 \\
\hline & $(0.04)$ & $(0.04)$ & $(0.04)$ \\
\hline \multirow{2}{*}{ Years experience as manager } & 1.002 & 1.009 & 1.011 \\
\hline & $(0.01)$ & $(0.01)$ & $(0.01)$ \\
\hline \multirow{2}{*}{ Previous start-up experience } & 1.030 & 0.966 & 1.047 \\
\hline & $(0.24)$ & $(0.25)$ & $(0.25)$ \\
\hline \multirow{2}{*}{ Parents in business } & 0.827 & 0.847 & 0.835 \\
\hline & $(0.21)$ & $(0.22)$ & $(0.22)$ \\
\hline Encouraged by & $1.743 * *$ & $1.593^{\dagger}$ & $1.631 * *$ \\
\hline friends or family & $(0.24)$ & $(0.25)$ & $(0.25)$ \\
\hline \multirow{2}{*}{ Gender $(f=1)$ (italic?) } & $0.658^{\dagger}$ & $0.647^{\dagger}$ & $0.595 * *$ \\
\hline & $(0.23)$ & $(0.24)$ & $(0.24)$ \\
\hline \multirow{2}{*}{ Financial institution } & $1.766 * *$ & 1.366 & 1.377 \\
\hline & $(0.24)$ & $(0.25)$ & $(0.25)$ \\
\hline \multirow{2}{*}{ Gestation behaviors } & $0.1 .368 * * *$ & $1.419 * * *$ & $0.346 * * *$ \\
\hline & $(0.05)$ & $(0.05)$ & $(0.05)$ \\
\hline \multirow{2}{*}{ Contact with assistance agency } & & $1.715 * *$ & $1.977 * *$ \\
\hline & & $(0.20)$ & $(0.31)$ \\
\hline \multirow{3}{*}{ Business classes Taken } & & 1.376 & $2.242 * * *$ \\
\hline & & $(0.22)$ & $(0.31)$ \\
\hline & & 1.164 & 1.145 \\
\hline Manufacturing & & $(0.39)$ & $(0.41)$ \\
\hline \multirow[t]{2}{*}{ USA1 } & & $-0.689 * * *$ & 0.902 \\
\hline & & $(0.502)$ & $(0.341)$ \\
\hline Agency $*$ US & & & 0.593 \\
\hline Agency "US & & & $(0.51)$ \\
\hline Business class * US & & & $0.361 * *$ \\
\hline & & & $(0.45)$ \\
\hline Manufacturing * US & & & 0.783 \\
\hline & & & $(1.279)$ \\
\hline-2 log likelihood & 609.5 & 585.054 & 578.172 \\
\hline Model X ${ }^{2}$ & $108.8 * * *$ & $132.3 * * *$ & $140.2 * * *$ \\
\hline$D f$ & 8 & 12 & 15 \\
\hline Overall hit rate & $81.0 \%$ & 81.8 & $81.9 \%$ \\
\hline Nagelkerke $\mathrm{R}^{2}$ & 0.223 & 0.267 & 0.282 \\
\hline $\mathrm{N}$ & 709 & 709 & 709 \\
\hline
\end{tabular}

Odds ratios (ExpB) are expressed first, Standard errors are in parentheses. ${ }^{\dagger} p<0.1 ; * p<0.05 ; * * p<0.01$; $* * * p<0.001$. 
Equation 1 examines control variables predicting the probability of a nascent entrepreneur writing a formal written business plan. The goodness of fit Chi -square of 108.8 tests the null hypothesis that the coefficients for all of the terms in this model, except the constant, are zero (like an " $f$ test" in regression). Being encouraged by friends or family, making contact with a financial institution, and number of gestation behaviors were control variables that demonstrated statistically significant results. We also controlled for years of education, experience as a manager, previous start-up experience, and gender, in the models. Gender was significant on the $10 \%$ level and negative.

Equation 2 shows the results of adding contact with an assistance agency, business classes, manufacturing and country to the model. Noteworthy is that assistance from financial institutions became negative as the independent variables were added. The effect of contact with the assistance agency was significant as well as country. The full model remained strong, Chi-square of 136 statistically significant, and the Nagelkerke $\mathrm{R}^{2}$ showing an improvement to 0.28 , despite the added degrees of freedom. Converting probability, more commonly referred to as "odds", is simply a matter of taking the coefficient to the $\mathrm{e}^{\mathrm{x}}$. Thus, those nascents who have had contact with an assistance agency increase the odds of their writing a formal business plan by a factor of $66 \%$ Hypothesis $1 \mathrm{a}$ stated that nascent organizations whose founders contact public support agencies have a greater propensity to produce business plans than those without such contact. We interpret this finding as confirming H1a. Having taken a business class had a positive coefficient and was not significant. We interpret this as rejecting $\mathrm{H} 1 \mathrm{~b}$ for the entire sample population. Finally, manufacturing was not found to be statistically significant. Thus, H1c was rejected.

Equation 3 adds interaction variables to test for the moderating influence of the US, specifically, agency contact multiplied by US, business class multiplied by US, and Manufacturing multiplied by US. The Nagelkerke $\mathrm{R}^{2}$ shows weak improvement despite the additional degrees of freedom to 0.28 , and the chi square is statistically significant at 145 . The interaction terms for agency or manufacturing failed to demonstrate statistical significance, although they are in the correct direction. Thus, H2a and $\mathrm{H} 2 \mathrm{c}$ were not supported. However, the coefficient for the moderating variable for business class and US was both statistically significant and strong. Those nascents from the US who took classes were almost three times less likely to write business plans than Swedish nascent entrepreneurs who had taken business planning classes. Thus, H2b was upheld, showing the moderating influence of US culture on the likelihood to plan.

\section{Discussion}

In this study, we examined and compared, cross-nationally, factors leading two different populations of nascent entrepreneurs to engage in formal written business planning. Research regarding nascent entrepreneurs is, in itself, very much in its nascence, and accordingly, we believe these findings to be of considerable interest to scholars, consultants, and practitioners. Our theoretical perspective utilizes institutional theory, highlighting isomorphic organizational trends world-wide, informed by the historical and cultural differences between Sweden and the US. In the setting of businesses practice, which essentially is open market based in both countries, institutional pressures influence the nascent organizations differently. While institutional pressures are effective in directing Swedish nascents towards writing business plans, it is less effective in the US. Although the business planning institution 
is older in the US, and more widely diffused in American management literature, business planning adoption rates are significantly higher in Sweden. This indicates that the Swedish diffusion of business planning, via institutional pressures, has been more effective, over all. This becomes particularly true given that the business plan phenomena is relatively younger in Sweden than in the US. It has previously been found that regulations in the US, while often stricter than in other countries, are not necessarily more effective [65]. Our study indicates that nascent organizations in the US are also less prone to acquiesce to institutional pressures in general and to normative pressures in specific. The primary driver for the difference found in this study is that business education in Sweden seems to very effectively promote business plan writing.

An important consideration for the reader is to note that our position towards the values of written business plans is healthily skeptical. Research has yet to conclude whether or not the planning process provides any technical or organizational efficiency gains [10,19,22]. Despite our skepticism, our findings suggest both the practices and the causes of planning have certain similarities across two different cultural and national divides. We offer the first confirmatory evidence regarding the generalizability of certain nascent behaviors, as well as differentiating factors that appear to be somewhat more culturally or environmentally determined.

In this research, we identified specific environmental characteristics that increased the probability of nascent entrepreneurs engaging in formal business planning. Those who had contact with assistance agencies were significantly more likely to engage in business planning. We interpret this phenomenon as expressing primarily regulative aspects of institutionalization. We do not view this finding to be a result of formal requirements along the road to the establishment of a firm, such as business registration and laws regulating health and public welfare. Rather, we believe nascent entrepreneurs voluntarily comply with practices and formalized routines established by banks, assistance agencies and incubators. Should further research determine that formal written plans do not provide any particular gains or efficiencies; the ability to reduce or limit planning activities will be constrained by the established field of actors already teaching, promoting, evaluating, and demanding business plans.

\section{Limitations}

This study represents one of the very first studies systematically analyzing differences in institutional responses to business planning in two countries. As such, it is not without limitations. We acknowledge that the operationalization of institutional variables would benefit from more close grained questions with respect to institutional pressures. Preferably, each institutional concept would be tested with several questions and examined for reliability. Unfortunately, our data does not allow for such analysis. On the other hand, it does present a unique, comparative database with respect to nascent entrepreneurs in the two different countries.

When examined by country, we found the impact quite robust in Sweden, but not statistically significant in the US. This confirmed our view that the institution of business planning was so deeply embedded in the cultural fabric that secondary sources of institutional pressure were of less importance. For example, fewer nascent entrepreneurs in the US were in contact with assistance agencies than their Swedish counterparts-only $15 \%$, versus $40 \%$ in Sweden, had such contact. Thus, while there may be many more opportunities for nascents to get assistance in Sweden than in the US, it 
may also reflect the lack of entrepreneurial institutional diffusion extant in the Swedish cultural and bureaucratic landscape. For example, in Sweden, the unemployment office assists nascent entrepreneurs in their activities. Our research shows that, in terms of scope and impact, normative practices appear to differ somewhat trans-nationally and trans-culturally. In particular, we believe we are observing a global isomorphic trend toward the overall promotion of entrepreneurial activities, demonstrating how and with what forces such isomorphism occurs.

Although we rejected our hypothesis regarding business education in general, the variable was significant and positive in the model with the moderating variables. There was a significant and distinct difference in how business education influenced US versus Swedish nascent entrepreneurs. Business education speaks directly to what many of us, as academics, are engaged in. It should hardly come as a surprise that our business school graduates are more inclined to write a formal plan than those not exposed. Our finding that individuals so exposed in Sweden were much more likely to plan than those who had completed courses in the US speaks to the general diffusion of the business planning paradigm in the US. Due to the historical precedence of business education in the US, and its relative newness in Sweden, we anticipated that graduates with Swedish business educations would have a greater propensity to plan than similar graduates from the US.

However, it may simply be the case that Swedish nascent entrepreneurs experience a different type of business education, either qualitatively or quantitatively, vis-à-vis business planning education than their US counterparts. We were unable to examine issues of content or quality in our study, and this research suggests the importance of future study. Finally, nascents in the US may be different from nascent entrepreneurs in Sweden. Differences may be due to cultural factors or environmental factors, including markets and resources. For example, we became aware of the role that the unemployment office plays in Sweden in promoting start-ups and nascent activities. In the US, the unemployment office does not, for the most part, play a comparable role in small business promotion.

We also found industrial sector (manufacturing) to be a relevant factor in predicting who would eventually complete a formal written business plan. While we found evidence of the role of industry sector in differentiating who would plan and who would not, it appeared that, as with business classes, the effects were primarily relegated to the Swedish cohort of nascent entrepreneurs. Note the very small numbers of individuals in the US population engaged in manufacturing (1\% versus $11 \%$ in the Swedish case). We accede that a more cogent and logical argument for the necessity of formal planning may be made for well known complex activities such as manufacturing, where the combination of resource constraints and timing present particular obstacles toward successful implementation. For example, plants, machinery, and human resources are often critical aspects of the operational plan, while innovation and unknown market components are likely to occur either earlier or later in the product cycle. However, even mature manufacturing processes are subject to significant adaptation and ongoing innovation, both factors nearly impossible to predict in the business plan format. For this reason, we interpret our findings as reflecting the higher levels of institutionalization evident in certain (manufacturing) fields in Sweden. We expected this mimetic behavior to be a result of commonly assumed best practices in well-established fields, such as manufacturing. Given that a higher percentage of Swedish nascent entrepreneurs enter into manufacturing businesses, our findings regarding the differences between the two populations may simply represent the different mix of nascent activities under study. 
Thus, we found our institutional predictors to be stronger, in general, for the Swedish population than for that of the US. It may be that an institutional framework is less effective in predicting the behavior of US entrepreneurs. Perhaps Americans are less likely to be subjected to institutional pressures, and more likely to follow their own path(s). Such an explanation fits well with a popular understanding of the American cultural mentality as free and independent. Further, alternative cultural frameworks that support the individual agent as profit maximizing may be a better predictor of business planning in the US setting than in Sweden. Perhaps, entrepreneurs in the US entrepreneurs write business plans because it is efficient to do so, while in Sweden they do so because it is institutionally demanded. However, there may also be institutional explanations as to why we find weaker results in the US cases. Based on the higher proportion of business planners and the longer history of business planning in the US, we suspect that institutional forces play a greater role. It may simply be that other institutional sources, unmeasured in this study, such as pressure from investors to write business plans, or normative expectations due to the more established expectations of writing business plans, work stronger in the US setting. For example, there may be a stronger pressure to write business plans from venture capitalists and angel investors in the US. This also presents an area for future study. From an institutional theoretical perspective, we suspect that the further institutionalized a phenomena is in any particular environment, the less strength there will be in single measure predictors of institutional forces. As institutions become increasingly taken for granted, additional sources of institutionalization reinforce and supplement each other.

\section{Conclusions}

Although the debate regarding the importance of early start-up planning is as yet unresolved, our study has implications for adherents of both sides of the argument. For those that maintain planning is essential, efficient, desirable, and very important, we offer evidence regarding the most effective modes to promote planning activities. These appear to take place through assistance organizations. For those who view planning as a largely futile exercise providing little if any competitive advantages, we provide evidence regarding the impact of competing sources of diffusion and isomorphism. Such information should be useful for those attempting to prevent or moderate the spread and practice of start-up planning.

We suggest that future research examine the complex relationship between planning and performance cross-culturally in order to adjudicate between alternative explanations of planning behavior. A deeper understanding of how institutional forces influence entrepreneurs will also increase our knowledge regarding the relationship between institutions and behaviors in highly and less institutionalized environments.

\section{Conflicts of Interest}

The authors declare no conflict of interest. 


\section{References}

1. Bhide, A.V. The Origin and Evolution of New Businesses; Oxford University Press: New York, NY, USA, 2000.

2. Karlsson, T.; Honig, B. Judging a book by its cover: An institutional perspective on new ventures and the business plan. J. Bus. Ventur. 2009, 24, 27-45.

3. Perry, S. The relationship between written business plans and the failure of small business in the U.S. J. Small Bus. Manag. 2001, 39, 201-208.

4. March, J. Bounded rationality, ambiguity, and the engineering of choice. Rand J. Econ. 1978, 9 , 587-608.

5. Sarasvathy, S. Effectuation: Elements of Entrepreneurial Experience; Edward Elgar Publishing: Cheltenham, UK, 2008.

6. Sarasvathy, S.D. Causation and effectuation: Toward a theoretical shift from economic inevitability to entrepreneurial contingency. Acad. Manag. Rev. 2001, 26, 243-263.

7. Reynolds, P. Who starts firms? Preliminary explorations of firms in gestation. Small Bus. Econ. 1997, 9, 449-462.

8. Cassia, L.; de Massis, A.; Meoli, M.; Minola, T. Entrepreneurship research centers around the world: Research orientation, knowledge transfer and performance. J. Technol. Transf. 2013, 1-17, doi:10.1007/s10961-012-9290-7.

9. Davidsson, P.; Hunter, E.; Klofsten, M. Institutional forces: The invisible hand that shapes venture ideas? Int. Small Bus. J. 2006, 24, 115-131.

10. Honig, B. Learning Strategies and resources for entrepreneurs and intrapreneurs. Entrep. Theory Pract. 2001, 26.1, 21-35.

11. Radosevic, S.; Yoruk, E. Entrepreneurial propensity of innovation systems: Theory, methodology and evidence. Res. Policy 2013, 42, 1015-1038.

12. Zimmerman, M.; Zeitz, G. Beyond survival: Achieving new venture growth by building legitimacy. Acad. Manag. Rev. 2002, 27, 414-431.

13. Aldrich, H.; Fiol, M. Fools rush in? The institutional context of industry creation. Acad. Manag. Rev. 1994, 19, 645-670.

14. Singh, J.V.; Tucker, D.J.; House, R.J. Organizational legitimacy and the liability of newness. Adm. Sci. Q. 1986, 31, 171-193.

15. Suchman, M.C. Managing legitimacy: Strategic and institutional approaches. Acad. Manag. Rev. 1995, 20, 571-610.

16. Stryker, R. Rules, resources and legitimacy processes: Some implications for social conflict order and change. Am. J. Sociol. 1994, 99, 847-910.

17. Aldrich, E.H.; Ruef, M. Organizations Evolving; Sage Publications: Thousand Oaks, CA, USA, 2006.

18. Statistics Sweden. Associational Life in Sweden: General Welfare Production, Social Capital, Training in Democracy; Report no. 98 on Living Conditions; Statistics Sweden: Stockholm, Sweden, 2003.

19. Delmar, F.; Shane, S. Legitimating first: Organizing activities and the survival of new ventures. $J$. Bus. Ventur. 2004, 19, 385-410. 
20. Delmar, F.; Shane, S. Does business planning facilitate the development of new ventures? Strateg. Manag. J. 2003, 24, 1165-1185.

21. Liao, J.; Gartner, W. The effects of pre-venture plan timing and perceived environmental uncertainty on the persistence of emerging firms. Small Bus. Econ. 2006, 27, 23-40.

22. Castrogiovanni, G. Pre-startup planning and the survival of new small businesses: Theoretical linkages. J. Manag. 1996, 22, 801-822.

23. Heugens, P.; Lander, M. Structure! Agency! (and other quarrels): A meta-analysis of institutional theories of organization. Acade. Manag. J. 2009, 53, 61-85.

24. Meyer, J.W.; Rowan, B. Institutionalized organizations: Formal structure as myth and ceremony. Am. J. Sociol. 1977, 83, 340-363.

25. Mizruchi, M.S.; Fein, L.C. The social construction of organizational knowledge: A study of the uses of coercive, mimetic and normative isomorphism. Adm. Sci. Q. 1999, 44, 653-683.

26. Honig, B.; Karlsson, T. Institutional forces and the written business plan. J. Manag. 2004, 30, $29-48$.

27. Oliver, C. Strategic responses to institutional processes. Acad. Manag. Rev. 1991, 16, 145-179.

28. Parsons, T. Suggestions for a sociological approach to the theory of organizations, I and II. Adm. Sci. Q. 1956, 1, 225-239.

29. Aldrich, H. Organizations Evolving; Sage Publications: London, UK, 1999.

30. DiMaggio, P.; Powell, W. The iron cage revisited: Institutional isomorphism and collective rationality in organizational fields. Am. Sociol. Rev. 1983, 48, 147-160.

31. Reynolds, P.D.; Hay, M.; Bygrave, W.D.; Camp, S.M.; Autio, E. Global Entrepreneurship Monitor. Available online: http://www.gemconsortium.org/docs/download/657 (accessed on 12 October 2013).

32. Karnoe, P. Institutional Interpretations and Explanations of Differences in American and Danish Approaches to Innovation; Sage Publications: Thousand Oaks, CA, USA, 1995.

33. Scott, W.R. Institutions and Organizations; Sage Publications: Thousand Oaks, CA, USA, 2001.

34. Campbell, J.L.; Lindberg, L.N. Property rights and the organization of economic activity by the state. Am. Sociol. Rev. 1990, 55, 634-647.

35. Barnett, W.P.; Carroll, G.R. Competition and mutualism among early telephone companies. Adm. Sci. Q. 1987, 32, 400-421.

36. Honig, B. Entrepreneurship education: Toward a model of contingency-based business planning. Acad. Manag. Learn. Educ. 2004, 3, 258-273.

37. Scott, R.W.; Backman, E.V. Institutional Theory in the Medical Care Sector. In Innovations in Health Care Delivery: Insights for Organization Theory; Mick, S.S., Ed.; Jossey-Bass Publishing: San Francisco, CA, USA, 1990.

38. DiMaggio, P. Constructing an Organizational Field as a Professional Project: US Art Museums, 1920-1940. In The New Institutionalism in Organizational Analysis; Powell, W.W., DiMaggio, P.J., Eds.; The university of Chicago press: Chicago, IL, USA, 1991.

39. Brint, S.; Karabel, J. Institutional Origins and Transformations; The Case of American Community Colleges. In The New Institutionalism in Organizational Analysis; Powell, W.W., DiMaggio, P.J., Eds.; The University of Chicago Press: Chicago, IL, USA, 1991.

40. Kuratko, D.F.; Hodgetts, R.M. Entrepreneurship: A Contemporary Approach; Harcourt School Publishers: Orlando, FL, USA, 2001. 
41. Lambing, P.; Kuehl, C.R. Entrepreneurship; Prentice Hall: Upper Saddle River, NJ, USA, 2000.

42. Stinchcombe, A.L. Social Structure and Organizations. In Handbook of Organizations; March, J.G., Ed.; Rand McNally \& Company: Stanford, CA, USA, 1965; pp. 153-193.

43. Timmons, J.A. New Venture Creation: Entrepreneurship for the 21st Century; McGraw-Hill Publishing: Boston, MA, USA, 1999.

44. Zacharakis, A.; McMullen, J.; Shepherd, D. Venture capitalists' decision policies across three countries: An institutional perspective. J. Bus. Ventur. 2007, 38, 691-708.

45. Haunschild, P. How much is that company worth? Interorganizational relationships, uncertainty, and acquisition premiums. Adm. Sci. Q. 1994, 44, 391-411.

46. Haverman, H.A. Follow the leader: Mimetic isomorphism and entry into new markets. Adm. Sci. Q. 1993, 38, 593-627.

47. Brown, S. Manufacturing strategy, manufacturing seniority and plant performance in quality. Int. J. Oper. Prod. Manag. 1998, 18, 565-587.

48. Lampel, J.; Shamsie, J. Critical push: Strategies for creating momentum in the motion picture industry. J. Manag. 2000, 26, 233-257.

49. Jones, C. Co-evolution of entrepreneurial careers, institutional rules and competitive dynamics in American film, 1895-1920. Organ. Stud. 2001, 22, 911-944.

50. Burdos, A. An institutional theory of organizational retrenchment: Adoption of early faculty retirement programs among Ontario universities. Can. J. Adm. Sci. 2001, 18, 221-236.

51. Mezias, S.J. An institutional model of organizational practice: Financial reporting at the Fortune 200. Adm. Sci. Q. 1990, 35, 431-457.

52. Wickham, P. Strategic Entrepreneurship: A Decision-Making Approach to New Venture Creation and Management; Pearson Education: Harlow, UK, 2001.

53. Ketokivi, M.; Schroeder, R. Strategic, structural contingency and institutional explanations in the adoption of innovative manufacturing practices. J. Oper. Manag. 2004, 22, 63-89.

54. Pil, F.; Macduffie, P. The adoption of high-involvement work practices. Ind. Relat. 1996, 35, 423-455.

55. Daun, Å. Swedish Mentality, 5th ed.; The Pennsylvania State University Press: University Park, PA, USA, 2006.

56. Putnam, R.D. Democracies in Flux: The Evolution of Social Capital in Contemporary Society; Oxford University Press: New York, NY, USA, 2002.

57. Falkenhall, B.; Johansson, M.; Olofsson, J. Utvärdering av de näringslivspolitiska effekterna av stöd till start av näringslivsverksamhet (in Swidish); Institutet för Tillväxtpolitiska Studier: Östersund, Sweden, 2003.

58. UNESCO. Unesco Annual Statistical Yearbook; UNESCO: Paris, France, 1995.

59. Wesphal, J.; Gulari, R.; Shortell, S. Customization or conformity? An institutional and network perspective on the content and consequences of TQM adoption. Adm. Sci. Q. 1997, 42, 366-394.

60. Bjerke, B. Förklara eller förstå entreprenörskap? (in Swidish) Studentlitteratur: Lund, Sweden, 2005.

61. Katz, J. The chronology and intellectual trajectory of American entrepreneurship education 1876-1999. J. Bus. Ventur. 2003, 18, 283-300.

62. Karlsson, T. Business Plans in New Ventures: An Institutional Perspective. Ph.D. Dissertation, Jönköping University, Jonkoping, Sweden, September 2005. 
63. Ingenjörsvetenskapsakademin. Så skriver du en vinnande affärsplan: En praktisk handledning (in Swidish), 2nd ed.; Connect, Svenska riskkapitalföreningen, OH tryckeri: Stockholm, Sweden, 2004.

64. Kubr, T.; Ilar, D.; Marchesi, H. Affärsplanen (in Swidish); Ekerlids Förlag: Stockholm, Sweden, 1999.

65. Johnson, A.K. The influence of institutional culture on the formation of pre-regime climate change policies in Sweden, Japan and the United States. Environ. Values 1998, 7, 223-244.

66. Stevenson, H.H.; Grousbeck, H.I.; Roberts, M.J.; Bhide, A. New Business Ventures and the Entrepreneur; McGraw-Hill Publishing: Boston, MA, USA, 1999.

67. Carter, N.; Gartner, W.; Reynolds, P. Exploring start-up event sequences. J. Bus. Ventur. 1996, $11,151-166$.

68. Katz, J.; Gartner, W. Properties of emerging organizations. Acad. Manag. Rev. 1988, 13, 429-441.

69. UNESCO. Unesco Annual Statistical Yearbook; UNESCO: Paris, France, 1980.

70. Gartner, W.; Shaver, K.; Carter, N.; Reynolds, P. Handbook of Entrepreneurial Dynamics: The Process of Business Creation; Sage Publications: London, UK, 2004.

71. Abrahamson, E. Managerial fads and fashions: The diffusion and rejection of innovations. Acad. Manag. Rev. 1991, 16, 586-612.

72. Becker, G.S. Human Capital; The University of Chicago Press: Chicago, IL, USA, 1964.

73. Schultz, T.W. Investment in man: An economist's view. Soc. Serv. Rev. 1959, 33, 109-117.

74. Coleman, J. Social capital in the creation of human capital. Am. J. Sociol. 1988, 94, 95-120.

75. Lin, N.; Ensel, W.; Vaughn, J. Social resources and strength of ties: Structural factors in occupational status attainment. Am. Sociol. Rev. 1981, 46, 393-405.

76. Portes, A. Social capital. Annu. Rev. Sociol. 1998, 24, 43-68.

77. Bates, T. Self-employment entry across industry groups. J. Bus. Ventur. 1995, 10, 143-156.

78. Brush, C.; Hirsrich, R. Antecedent influences on women-owned businesses. J. Manag. Psychol. 1991, 6, 9-16.

79. Criaco, G.; Minola, T.; Migliorini, P.; Serarols-Tarrés, C. "To have and have not": founders' human capital and university start-up survival. J. Technol. Transf. 2013: 1-27, doi:10.1007/s10961-013-9312-0.

80. Davidsson, P.; Honig, B. The role of social and human capital among nascent entrepreneurs. J. Bus. Ventur. 2003, 18, 301-331.

81. Mayer-Haug, K.; Read, S.; Brinckmann, J.; Dew, N.; Grichnik, D. Entrepreneurial talent and venture performance: A meta-analytic investigation of SMEs. Res. Policy 2013, 42, 1251-1273.

82. Hosmer, D.; Lemeshow, S. Applied Logistic Regression; John Wiley and Sons: New York, NY, USA, 1989. 


\section{Appendix (A)}

\section{Unweighted Correlations}

\begin{tabular}{|c|c|c|c|c|c|c|c|c|c|c|c|c|c|c|c|}
\hline & & Mean & S.D & 1 & 2 & 3 & 4 & 5 & 6 & 7 & 8 & 9 & 10 & 11 & 12 \\
\hline 1 & Business plan & 0.205 & 0.404 & & & & \multicolumn{9}{|c|}{ ** Correlation is significant at the 0.01 level (2-tailed). } \\
\hline 2 & Education & 13.943 & 2.662 & 0.022 & & & \multicolumn{9}{|c|}{ * Correlation is significant at the 0.05 level (2-tailed). } \\
\hline 3 & Management exp & 6.900 & 8.068 & $0.098(* *)$ & $0.223(* *)$ & & & & & & & & & & \\
\hline 4 & Start up exp & 0.233 & 0.423 & 0.033 & $0.106(* *)$ & $0.103(* *)$ & & & & & & & & & \\
\hline 5 & Parent in Bus & 0.495 & 0.500 & 0.021 & 0.026 & 0.051 & $0.156(* *)$ & & & & & & & & \\
\hline 6 & Encouragement & 0.684 & 0.465 & $0.092(* *)$ & $-0.079(*)$ & -0.045 & 0.010 & $0.099(* *)$ & & & & & & & \\
\hline 7 & Gender & 0.344 & 0.475 & -0.058 & 0.060 & -0.047 & -0.067 & 0.005 & -0.003 & & & & & & \\
\hline 8 & Financial institution & 0.212 & 0.409 & $0.242(* *)$ & 0.023 & $0.101(* *)$ & 0.043 & $0.090(*)$ & $0.070(*)$ & $-0.071(*)$ & & & & & \\
\hline 9 & Gestation behavior & 4.690 & 2.673 & $0.357(* *)$ & $0.139(* *)$ & $0.230(* *)$ & $0.128(* *)$ & $0.120(* *)$ & 0.047 & -0.022 & $0.425(* *)$ & & & & \\
\hline 10 & Agency contact & 0.285 & 0.452 & $0.160(* *)$ & -0.024 & -0.047 & 0.005 & -0.035 & $0.102(* *)$ & 0.062 & $0.203(* *)$ & 0.060 & & & \\
\hline 11 & Business class & 0.378 & 0.485 & $0.109(* *)$ & $0.105(* *)$ & 0.055 & -0.015 & -0.025 & 0.035 & $0.081(*)$ & $0.099(* *)$ & $0.099(* *)$ & $0.233(* *)$ & & \\
\hline 12 & Manufacturing & 0.065 & 0.246 & $0.150(* *)$ & -0.05 & 0.039 & $0.070(*)$ & 0.008 & 0.052 & $-0.098(* *)$ & $0.206(* *)$ & $0.102(* *)$ & $0.146(* *)$ & 0.014 & \\
\hline 13 & US & 0.492 & 0.500 & $-0.070(*)$ & $0.415(* *)$ & $0.231 * *$ & 0.041 & 0.029 & $-0.182 * *$ & $0.115^{* *}$ & -0.014 & $0.256 * *$ & $-0.277 * *$ & $-0.077 * *$ & $-0.195 * *$ \\
\hline
\end{tabular}




\section{Appendix B. The Relevant Questions}

Business plan: What is the current form of your business plan (formally written 1; Else 0)?

Business assistance: Contact with government agency (if yes 1, else 0)

Business courses: Please write the number of courses you have taken in the following area. If economics or business administration, then 1 , else 0

Manufacturing: Would you consider this new business to be in manufacturing, construction, agriculture, mining or something else? (if manufacturing 1 , else 0 )

Management experience: For how many years, if any, did you have managerial, supervisory, or administrative responsibilities?

Education: What is the highest level of education you have completed so far (recoded as years)

Previous start up experience: How many other businesses have you helped to start? (more than $0=1$; else 0)

Parents in business: Did your parents ever work for themselves or run their own businesses, alone or together? (if any, 1; else 0)

Family support: Have your family, relatives or other close friends been encouraging you, or discouraging you from starting a business of your own ( 1 for encouraging 0 for discouraging and mixed)

Gender: Interviewer coded gender: Female 1, Male 0

Financial institutions: Have financial institutions or other people been asked for funds? (if yes, 1 else 0 )

Gestation behaviors (15 questions)

Example: Have marketing or promotional efforts been started (for the product or service this startup will be selling)? (if yes 1 , else 0 ) The category gestation behavior was made out of the sum of all 15 questions.

Equipment: Have any major items like equipment, facilities, or property been purchased, leased or rented for the new start/up (Major: any item with retail value or sale value of $\$ 1000$ or more)? (yes $1=$ No 0 )

(C) 2013 by the authors; licensee MDPI, Basel, Switzerland. This article is an open-access article distributed under the terms and conditions of the Creative Commons Attribution license (http://creativecommons.org/licenses/by/3.0/). 